\title{
Balint's Syndrome
}

\author{
CHANTAL O. HAUSSER, FRANÇOISE ROBERT, and NORMAND GIARD
}

SUMMARY: Balint's syndrome is usually attributed to bilateral parieto-occipital lesions. In several reported cases involvement of the frontal lobes was also documented and could be responsible for the "spasmodic fixation" often recorded in these patients. We report a case of Balint's syndrome in a patient with bilateral frontal and parieto-occipital metastases demonstrated by CT scan and confirmed by postmortem examination.

RESUMÉ: Le syndrome de Balint caractérisé par la paralysie psychique du regard. l'ataxie optique et un trouble de l'attention visuelle, est généralement attribué à des lésions pariéto-occipitales bilatérales. Dans quelques cas, il y a également une atteinte des lobes frontaux qui serait responsable de la "fixation spasmodique" que présentent certains malades. L'observation d'un malade souffrant de ce syndrome nous a permis de démontrer par la tomodensitométrie (CT scan) et de confirmer par l'examen pathologique des métastases frontales et pariéto-occipitales bilatérales provenant d'un épithélioma bronchique.

From the Divisions of Neurology and Neuropathology, Notre-Dame Hospital and University of Montreal, Montreal, Canada.

Reprint requests to Dr. F. Robert, Department of Pathology, Notre-Dame Hospital, 1560 Sherbrooke Street East, Montreal, Quebec, Canada, H2L 4K8.

\section{INTRODUCTION}

Balint (1909) described a syndrome characterized by hemispheric paralysis of visual fixation, optic ataxia and disturbance of visual attention in a patient with bilateral occipito-parietal softenings. In the seventeen cases published since, bilateral lesions have been found mostly in the parietooccipital lobes, sometimes in association with frontal lesions. Post-mortem studies have revealed these lesions to be softenings (Balint, 1909; Hecaen and Ajuriaguera, 1954; Michel et al., 1965), gun-shot wounds (Holmes, 1918; Luria, 1959), Balo's leucoencephalitis (Hecaen et al., 1950), tumor (Hecaen and Ajuriaguerra, 1954) and Creutzfeldt-Jakob's disease (Morita et al., 1975). We report a typical case of Balint's syndrome where pathological examination showed bilateral parietooccipital and frontal metastases from a bronchogenic carcinoma.

\section{CASE REPORT}

Our patient was a 56 year-old man admitted on January 10th, 1977 complaining of a progressive visual disturbance and disorientation of three weeks duration. His relatives had noted that he frequently bumped into doors and that he appeared clumsy. Past history was negative. He had been a heavy smoker for 40 years. The general examination revealed a tall, thin, somewhat dyspneic man. He was euphoric, disorientated, easily distractible, but was able to follow commands. Physical examination was normal. Blood pressure was 120/80. Fundi, visual acuity, and pupillary reflexes were normal. Neurological examination was normal except for a peculiar neuropsychological disturbance recognized as a Balint's syndrome.

\section{ELEMENTS OF BALINTS SYNDROME}

Hemispheric paralysis of visual fixation

In his room, the patient stared in front of him without looking at the interlocutor. He had the behavior of a blind man. When ordered to glance in the direction of a specific object he was unable to do so. Should an unexpected noise occur he would turn his head and glance in the right direction. He was unable to follow a moving object. Optokinetic nystagmus was absent.

\section{Optic Ataxia}

He was unable to grasp objects under visual control. He misreached targets. He explained he saw these objects but was unable to reach them. He had difficulty lacing his shoes when looking at them. His shirt was often inside out, but he knew how to dress himself step by step.

Disturbance of visual attention was more pronounced on his left side, but was present everywhere outside the foveal zone. He did not notice threatening gestures. There was no blink reflex. He could orientate himself when walking straight along the corridor, but was unable to find the entrance to his room. When presented with several geometrical figures drawn on the same card he saw only one or two of these although he identified each of them if presented separately. Confronted with a complex figure, composed of several subunits, he was completely unable to recognize it.

In addition to these signs the patient felt sometimes as if his eyes were locked in fixation and, indeed, the examiner was able to notice a spasmodic fixation. When an object entered his visual field, the patient would stare at it for a long time. 
The rest of the neuropsychological examination revealed diminished and hesitant speech. Writing was poor with wide letters of different size and at different levels, but the words were correct. He copied simple geometric figures but only after repeated stimulation.

\section{Laboratory findings}

Visual fields were concentrically diminished bilaterally. Biological tests were normal. Sedimentation rate was $23 \mathrm{~mm} /$ hour. Pulmonary investigation revealed a bronchogenic carcinoma in the left inferior lung extending to the hilar lymph nodes. A skull $X$-ray was normal. The EEG showed a moderate disturbance characterized by theta activity over both parietooccipital regions more marked on the left side. The $\mathrm{Tc}^{99}$ brain scan and the computerized tomography (C T) with sodium and meglumine diatrizoated enhancement disclosed four lesions, two parieto-occipital and two frontal bilaterally (Fig. 1).

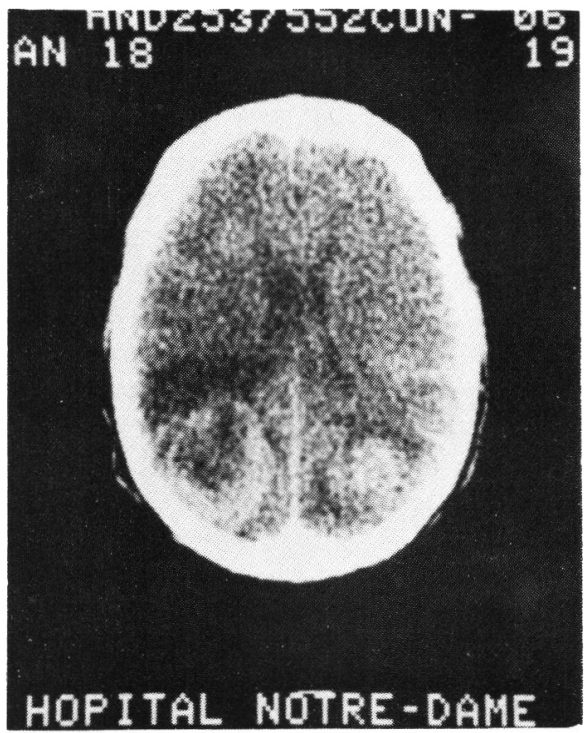

Figure $I-$ C.T. with sodium and meglumine diatrizoates enhancement shows two large parieto-occipital lesions and several frontal lesions.

\section{Evolution}

The patient improved with steroid therapy and was able to recognize a greater number of objects in his visual fields. However, because of a psychotic reaction steroids were discontinued. He died in February 1977.

\section{Post-mortem examination}

General autopsy revealed a bronchogenic carcinoma in the left inferior lobe with metastases to the hilar and paratracheal lymph nodes and to both adrenal glands.

The brain weighed $1450 \mathrm{~g}$. There was edema, but no herniation was seen. Seven metastases histologically identical with the lung tumor were identified in the cerebrum. Six of these were grossly symmetrical on each side of the midline. Two were superficial at the vertex, two were in the frontal lobes and measured $2 \mathrm{~cm}$ by $2 \mathrm{~cm}$ each (Fig. 2A). Two larger necrotic and hemorrhagic metastases measuring 5 $\mathrm{cm}$ by $4 \mathrm{~cm}$ by $5 \mathrm{~cm}$ each were seen in the parieto-occipital regions (Fig. 2B). The seventh lesion was small and located in the left corona radiata. Another metastasis was found in the left cerebellar white matter.

\section{DISCUSSION}

Balint (1909) described a patient suffering from bilateral parieto-occipital cerebral softening. The syndrome comprised: (I) hemisphere paralysis of visual fixation, the patient being unable to look toward a point within his peripheral visual fields despite absence of palsy of ocular movements or visual field defect. (2) optic ataxia or inability to execute coordinated voluntary movements in response to visual stimuli while movements under proprioceptive control were correctly performed. (3) impairment of attention to all visual stimuli. The patient's attention remained intact for nonvisual arousal.

Following Balint's description, seventeen additional cases have been reported. They are presented in table 1 . Holmes (1918) described five patients suffering from gun-shot wounds in the parieto-occipital regions bilaterally. These patients had disturbance of ocular movements and reflexes described as follows: a difficulty in fixing visual objects and in retaining the fixation when those objects were moved, failure to converge and accomodate for near objects and absence of the blink reflex. They also showed a disturbance of orientation and localization in space by sight and inability to estimate absolute and relative

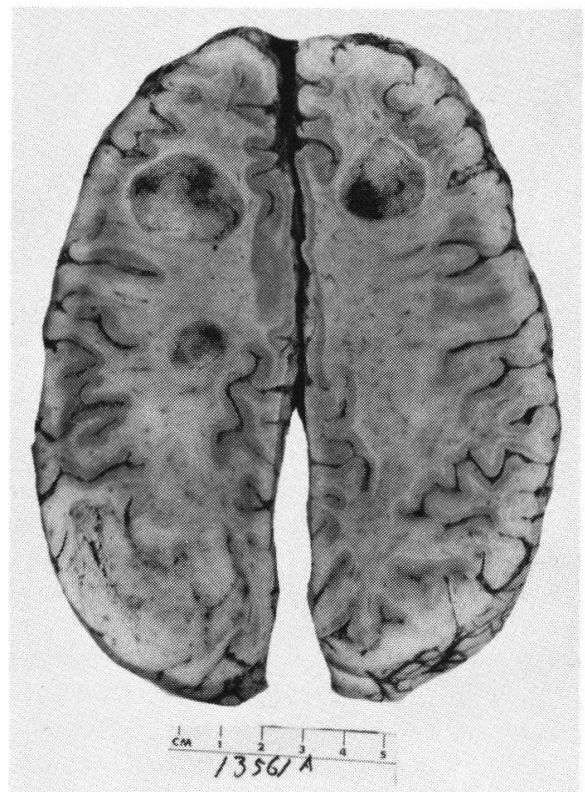

Figure $2 \boldsymbol{A}$ - Horizontal section of the brain, $3 \mathrm{~cm}$ from the convexity shows two frontal metastases, a small metastasis in the left corona radiata and a left parieto-occipital metastasis.

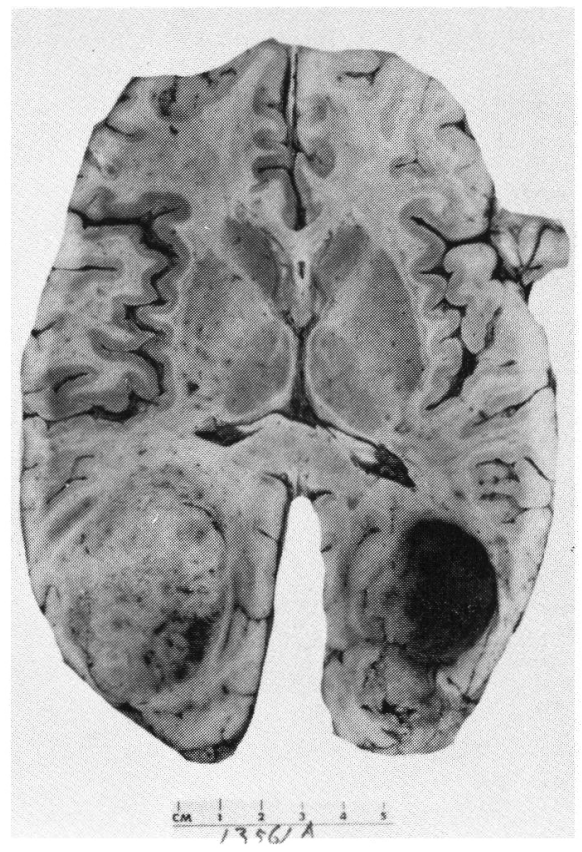

Figure $2 B-$ Horizontal section of the brain, $5 \mathrm{~cm}$ from the convexity, shows two parieto-occipital metastases. 
TABLE 1

Balint's Syndrome. Review of the Literature

\begin{tabular}{|c|c|c|c|c|}
\hline Authors & Age/Sex & Localization of Lesions & Nature of Lesions & $\begin{array}{l}\text { Post-Mortem } \\
\text { Examination }\end{array}$ \\
\hline Balint (1909) & $-/ M$ & $\begin{array}{l}\text { bilateral parieto-occipital } \\
\text { left rolandic gyrus }\end{array}$ & softenings & yes \\
\hline \multirow[t]{5}{*}{ Holmes (1918) } & $27 / M$ & bilateral supramarginal gyrus & gun-shot wound & no \\
\hline & $33 / \mathrm{M}$ & $\begin{array}{l}\text { right occipital lobe } \\
\text { left angular gyrus }\end{array}$ & gun-shot wound & yes \\
\hline & $-/ M$ & $\begin{array}{l}\text { right supramarginal gyrus } \\
\text { right precentral gyrus } \\
\text { left angular gyrus }\end{array}$ & gun-shot wound & no \\
\hline & $-/ M$ & $\begin{array}{l}\text { left supramarginal gyrus } \\
\text { extending to rolandic gyrus } \\
\text { right angular gyrus } \\
\text { right calcarine fissure }\end{array}$ & gun-shot wound & yes \\
\hline & $-/ M$ & bilateral parieto-occipital & gun-shot wound & no \\
\hline Hecaen et al (1950) & $33 / \mathrm{M}$ & $\begin{array}{l}\text { bilateral parieto-occipital } \\
\text { bilateral F3, right } F 2 \\
\text { bilateral atrophy }\end{array}$ & $\begin{array}{l}\text { Balo's leucoence- } \\
\text { phalitis }\end{array}$ & yes \\
\hline \multirow[t]{3}{*}{ (1954) } & $28 / F$ & $\begin{array}{l}\text { bilateral occipital } \\
\text { diffuse cortical atrophy }\end{array}$ & post-partum ischemia & no \\
\hline & $59 / F$ & bilateral parieto-occipital & astrocytoma & yes \\
\hline & $55 / \mathrm{M}$ & $\begin{array}{l}\text { left occipital } \\
\text { right occipital horn } \\
\text { left centrum ovale } \\
\text { bilateral frontal }\end{array}$ & $\begin{array}{l}\text { softening } \\
\text { metastasis } \\
\text { softening } \\
\text { metastasis }\end{array}$ & yes \\
\hline Luria (1959) & $21 / \mathrm{M}$ & bilateral parieto-occipital & gun-shot wound & yes \\
\hline Waltz (1961) & $35 / F$ & $\begin{array}{l}\text { bilateral diffuse cerebral } \\
\text { dysfunction }\end{array}$ & $\begin{array}{l}\text { post-partum } \\
\text { venous thrombosis }\end{array}$ & no \\
\hline $\begin{array}{l}\text { Saraux et al } \\
(1962)\end{array}$ & $15 / M$ & diffuse cortical dysfunction & cardiac arrest & no \\
\hline $\begin{array}{l}\text { Michel et al } \\
(1965)\end{array}$ & $51 / \mathrm{M}$ & $\begin{array}{l}\text { left fronto-parieto-occipital } \\
\text { bilateral fronto-parietal }\end{array}$ & $\begin{array}{l}\text { softening (recent) } \\
\text { softenings (old) }\end{array}$ & yes \\
\hline $\begin{array}{l}\text { Godwin-Austen } \\
\text { (1965) }\end{array}$ & $32 / F$ & bilateral parieto-occipital & $\begin{array}{l}\text { post-partum } \\
\text { venous thrombosis }\end{array}$ & no \\
\hline $\begin{array}{l}\text { Morita et al } \\
(1975)\end{array}$ & $55 / \mathrm{F}$ & $\begin{array}{l}\text { bilateral temporo-occipital } \\
\text { bilateral fronto-basal }\end{array}$ & Creutzfeldt-Jakob's & yes \\
\hline $\begin{array}{l}\text { Damasio and* } \\
\text { Benton (1979) }\end{array}$ & $42 / F$ & bilateral parieto-occipital & softenings & no \\
\hline
\end{tabular}

*In this patient Balint's syndrome was incomplete.

lengths and sizes. Like Balint's case, Holmes' patients had no impairment of visual fields or visual acuity. With the exception of his second case, in which the entrance wound was behind the parieto-occipital notch in the right occipital lobe, the lesions of Holmes' patients were either in the supramarginal gyrus bilaterally or in the supramarginal gyrus on one side and in the angular gyrus on the other side.
Hecaen and Ajuriaguerra (1954) described a minor Balint's syndrome in which the disturbance of visual attention and optic ataxia were unimportant or temporary. They emphasized the probable importance of frontal lesions in addition to bilateral parietooccipital lesions to obtain a classical, persistent Balint's syndrome. Since then, among 7 additional cases (Luria, 1959; Waltz, 1961; Saraux et al., 1962;
Michel et al., 1965; Godwin-Austen, 1965; Morita et al., 1975) only 3 had post-mortem examination (Luria, 1959; Michel et al., 1965; Morita et al., 1975). Two of them showed bilateral parieto-occipital lesion. The case described by Morita et al. (1975) had bilateral and frontal lesions, but these, caused by Creutzfeldt-Jakob's disease were not circumscribed.

Our patient, in addition to the three 
main elements of Balint's syndrome, i.e. paralysis of visual fixation, optic ataxia, and disturbance of visual attention, had a spasmodic fixation. This finding is not always reported in association with the other signs of the syndrome. Usually, this sign is related to frontal lesions in addition to the parieto-occipital lesions (Holmes, 1938). This spasmodic fixation is also associated with ocular apraxia observed in children with bilateral frontal malformation (Altrocchi and Menkes, 1960; Cogan and Adams, 1953, or in adults with acquired frontal lesions. Cogan (1969) emphasized the role of frontal lesions in Balint's syndrome. Frontal regions are responsible for the voluntary ocular movements and exert an inhibitive effect on the occipital centers. Thus, in the case of frontal lesions, spasmodic fixation might occur through a loss of inhibition of the occipital regions, as well as difficulty in looking at objects from lack of voluntary control.

Most cases of Balint's syndrome did not have frontal lesions, but had large parieto-occipital lesions (Balint, 1909; Holmes, 1918; Hecaen and Ajuriaguerra, 1954). Some authors therefore believe that Balint's syndrome is related to an interruption of parietooccipito-frontal connections controlling the sensory information transmitted to motor centers. Thus, optic ataxia, spatial disorientation, disturbance of visual attention and simultagnosia are better explained since these symptoms are of a sensory nature.

However, experimental section of occipito-frontal connections by leucotomy in monkeys has produced contralateral optic ataxia but without paralysis of fixation or disturbance of visual attention (Haaxma and Kuypers, 1975). The ablation of the region corresponding to the area 7 of Brodman in monkeys induced a misreaching with the hand contralateral to the lesion but this disturbance was temporary (Faugier-Grimaud and al., 1978). A human case of optic ataxia in the left visual fields after surgical removal of an arterial aneurysm from the wall of the right lateral ventricle was thought to be due to interruption of the occipito-frontal connections (Castaigne et al., 1971). A case of bilateral optic ataxia in a 47 year-old man was related to ischemic lesions located in the right frontal and left parietal lobes and in the posterior corpus collosum. This patient presented with impairment of oculomotor movements and behaved as a "blind man". In this case, similar to Balint's syndrome, the visual pathways were interrupted bilaterally (Boller et al., 1975).

Disturbance of visual attention is a behavioral disorder poorly elucidated. When it appears without hemianopsia it may be due to a neglect of an hemispatial field. In human cases with this finding Heilman and Valenstein (1978) showed that the lesions were either parietal, fronto-parietal or fronto-temporo-parietal, and induced a contralateral spatial agnosia. In the monkey experimental lesions of the dorsolateral frontal lobe and reticular formation produced a contralateral intentional akinesia without sensory or motor defect corresponding to hemispatial neglect (Watson et al., 1978). In the monkey it has also been shown that the area corresponding to area 7 of Brodman contains large sets of neurons that function by directing visual attention and exploration of the immediate surrounding extra-personal space (Mountcastle et al., 1975; Lynch et al., 1976). However, lesions in the inferior parietal lobule or in the superior temporal sulcus did not cause impairment of visual pattern discrimination in the monkey (Petrides and Iversen, 1979).

Simultagnosia, which is the inability of seeing several objects at the same time, is thought to depend upon a lesion of the anterior occipital regions (Godwin-Austen, 1965). Experiments of Luria (1959) showed that parietooccipital lesions reduced the excitability of the visual cortex and it could no longer record several simultaneous stimuli.

From these data we may infer the important contribution of bilateral parieto-occipital lesions in the pathogenesis of Balint's syndrome. We cannot exclude the role of the frontal lobe as shown by experimental and clinical investigations. Frontal lesions alone may be responsible for apraxia of gaze. When they are associated with parieto-occipital lesions they may add a further disconnection between anterior and posterior visual pathways further impairing oculomotor control. When the frontal lesions are present the Balint's syndrome is better defined and more persistent.

\section{REFERENCES}

ALTROCCHI, P.H. and MENKES, J.H. (1960). Congenital ocular motor apraxia. Brain, 83, 579-588.

BALINT, R. (1909). Seelenlahmung des "Schauens" optische Ataxia, raumliche Storung des Aufmerksamkeit. Monatsschrift fur Psychiatrie und Neurologie, 25, 51-81.

BOLLER, F., MONROE, C., YOUNGJAI, K., MACK, J.L. and PATAWARAN, C. (1975). Optic ataxia: clinical-radiological correlations with the EMIscan. Journal of Neurology, Neurosurgery and Psychiatry, 38, 954-958.

CASTAIGNE, P., PERTUISET, B., RONDOT, P. and RECONDO, J. (1971). Ataxie optique dans les deux hémichamps visuels homonymes gauches après exérese chirurgicale d'un anévrisme artériel de la paroi du ventricule latéral. Revue Neurologique, 124, 261-268.

COGAN, D.G. and ADAMS, R. D. (1953). A type of paralysis of conjugate gaze. Archives of Ophthalmology, 50, 434-442.

COGAN, D.G. (1969). Lesions involving conjugate lateral movements. In Neurology of the Ocular Muscles, pp. 106. Springfield, Illinois, Charles Thomas Publishers.

DAMASIO, A.R. and BENTON, A.L. (1979). Impairment of hand movements under visual guidance. Neurology, 29, 170-178.

FAUGIER-GRIMAUD, S., FRENOIS, C. and STEIN, D.G. (1978). Effects of posterior parietal lesions on visually guided behavior in monkeys. Neuropsychologia, 16, 151-168.

GODWIN-AUSTEN, R.B. (1965). A case of visual disorientation. Journal of Neurology, Neurosurgery and Psychiatry, 28, 453-458.

HAAXMA, R, and KUYPERS, J. M. (1975) Intrahemispheric cortical connexions and visual guidance of hand and finger movements in the rhesus monkey. Brain, 98, 239260.

HECAEN, H., AJURIAGUERRA, J., DAVID, M., ROUQUES, L., and DELL, M.D. (1950). Paralysie psychique du regard de Balint au cours de l'évolution d'une leucoencéphalite type Balo. Revue Neurologique, 83, 81-104.

HECAEN, $H$. and AJURIAGUERRA, J. (1954). Balint's syndrome (psychic paralysis of visual fixation) and its minor forms. Brain, 77, 373-400.

HEILMAN, K.M. and VALENSTEIN, E. (1978). Mechanisms underlying hemispatial neglect. Annals of Neurology, 5, 166-170.

HOLMES, G. (1918). Disturbances of visual orientation. British Journal of Ophthalmology, 2, 449-468.

HOLMES, G. (1938). The cerebral integration 
of ocular movements. British Medical Journal, 2, 107-112.

LURIA, A.R. (1959). Disorders of "simultaneous perception" in a case of bilateral occipito-parietal brain injury. Brain, 82, 437449.

LYNCH, J.C., MOUNTCASTLE, V. B., TALBOT, W. H. and YIN, T.C. (1977). Parietal lobe mechanisms for directed visual attention. Journal of Neurophysiology, 40, 363389.

MICHEL, F., JEANNEROD, M. and DEVIC, M. (1965). Troubles de l'orientation visuelle dans l'espace. (Á propos d'un cas anatomique). Cortex, 1, 441-466.

MORITA, Y., HAYASHI, S. and MIYOSHI, K. (1975). A case of Creutzfeldt-Jakob disease with Balint's syndrome. Brain and Nerve, 27, 1097-1103.

MOUNTCASTLE, V.B., LYNCH, J.C., GEORGOPOULOS, A., SAKATA, H. and ACUNA, C. (1975). Posterior parietal association cortex of the monkey: command function for operations within extrapersonal space. Journal of Neurophysiology, 38, 871908.
PETRIDES, M. and IVERSEN, S.D. (1979). Restricted posterior parietal lesions in the rhesus monkey and performance on visuospatial tasks. Brain Research, 161, 63-77.

SARAUX, H., ESTEVE, P., GRAVELEAU, D. and GOUPIL. H. (1962). Le syndrome de Balint et apraxie oculo-motrice. Annales d'Oculistique, 195, 456-472.

WALTZ, A.G. (1961). Dyspraxias of gaze. Archives of Neurology, 5, 638-647.

WATSON, R.T., MILLER, B.D. and HEILMAN, K.M. (1978). Nonsensory neglect. Annals of Neurology, 3, 505-508. 